\title{
NEW WAYS OF LEARNING IN HIGHER EDUCATION: MANAGING THE CHANGE
}

'There is nothing constant except change.' Heraclitus (ca 500 BC)

\begin{abstract}
Outside pressures, largely governmental, are increasingly forcing universities to change, in line with social changes in the environment in which they are embedded. This paper argues how such changes can be achieved in the particular case of the teaching function of universities, and why such changes so frequently fail to be achieved. The argument is based firmly on well established sociological theory, and it is illustrated by a largely successful change, the Enterprise in Higher Education Initiative. The change strategy which is derived from the theory leads to a number of maxims, and it is argued that while obeying these maxims is not a guarantee of success, disobeying them is an almost certain prescription for failure.
\end{abstract}

\section{INTRODUCTION}

It has frequently been pointed out (see e.g. Clark 1983, ch. 6) that universities have in the past been major agents of social change, while remaining remarkably traditional themselves. However, more recently, outside pressures, largely governmental, have increasingly forced universities too to change, in line with social changes in the environment in which they are embedded. Nowhere is this more clear than in the teaching function of universities, where massification, the demand for an education that is more relevant to the national economy and the movement towards life long learning all in different ways call for changes in the ways that universities, both corporately and individually, approach what is arguably their most important task, i.e. teaching. Such systemic changes are certain to come about; the question is whether they will be wholly imposed from outside or at least in part engendered from within. This paper will argue that if universities are to maintain a measure of control, they must follow certain systematic strategies for systemic change.

Tertiary Education and Management 5: 207-225, 1999.

(c) 1999 Kluwer Academic Publishers. Printed in the Netherlands. 
Universities abound in examples where attempts at systemic change were either perverted or wholly resisted, but there are also examples where such attempts were successful. Among the latter, probably the outstanding recent example in Britain is the Enterprise in Higher Education Initiative (EHE), which over the years 1989-1996 led to significant and apparently permanent changes in university curricula and - to some extent - in university culture. The purpose of this paper is to attempt an analysis of change processes and strategies, and to learn from practical examples why some strategies appear to be more successful than others. This will not be done through the post facto rationalisation of events, but through the development of a theory-based approach to change strategies, with brief reference to EHE as a practical example. The approach, which will lead to a list of pointers which may prove useful for change agents, will however grow in the first place out of an analysis of unsuccessful attempts at change.

\section{UnSUCCESSFUl ATTEMPTS AT CHANGE AND UNINTENDED CONSEQUENCES}

Social systems frequently respond to attempts to change them by creating secondary effects which may act so as to reduce or even negate the effectiveness of the primary effect. Even worse, the primary effects may act in the opposite way to that intended. A good example of the former arose in connection with changes in the provision of criminal justice for children (Thorpe 1983), where measures designed to reduce the number of children who received custodial sentences actually led to an increase in that number, due to previously non-custodially sentenced children now being sentenced custodially; a good example of the latter has been the use of performance indicators to increase an organisation's cost effectiveness which in the event led to a decrease (Pollitt 1987). This phenomenon of unintended negative consequences has in fact been so common that it has led to the formulation of the law of unintended consequences that 'Social systems frequently respond to change in the opposite way to that intended by those who initiated the change' (Tutt 1985). While this new law may be considered no more than a special case of Murphy's famous law that anything that can go wrong will go wrong, this is in fact not so and an analysis of the circumstances under which Tutt's law is valid can lead to ways of circumventing it. Such an analysis will generally find that most unsuccessful attempts at change arise from the application of a change model, which assumes simplistic cause and effect mechanisms between change measures applied directly to a part of a social system which it is designed to change and their effect on that part of the system. However, 
the latter is usually coupled strongly to the system as a whole or at least to other parts of it, so that the secondary effects, which arise as the primary effect impacts on the system as a whole, cannot be ignored. They must therefore be taken into account from the very beginning of attempting a change, and as this is often not easy, it is frequently not done.

\section{The Idea of A Force Field In A Social System}

In view of Tutt's law, any integrated approach to change strategies must start with the recognition, due originally to Lewin (1952), that in any change process in a social system it is necessary to consider not only the forces at the point of change, but as far as possible all the forces in the system. Furthermore, the system had in essence been stable before the attempt was made to change it, and any stable system which is disturbed in the first place tries to return to its former stability. The result is that the forces which previously ensured the stability of the system will now act so as to reestablish that stability, i.e. they will oppose the change. Not surprisingly, therefore, the majority of these forces will oppose the force which initiated the change in the first place, and it is this which leads to Tutt's law. Fortunately, there are usually some forces in the system which react positively to the attempted change and these forces then tend to increase. Any successful change strategy must take advantage of them in order to destabilise the old system and create a new stability in the changed system. The question - and it is the fundamental question to be tackled in this paper - is how to develop change strategies which are successful. 'Successful' here is purely instrumental, i.e. a change strategy is successful, if the resulting change is in line with the original change objectives.

There is therefore a continuously changing balance between the forces which support the change and those which oppose it. As the drivers of change invariably have more control over the supporting than over the opposing forces, they tend to increase the former with the inevitable consequence of the latter also increasing, which is usually a recipe for disaster. The alternative strategy, which involves the drivers of change attempting to reduce the opposing forces, over which they generally have little or no control, may be a difficult one to pursue, but it is the only one which is likely to lead to success. It certainly requires patience and time, as was well expressed for universities by Ashby (1964), perhaps not surprisingly in a slightly veiled fashion and in an address given in the United States:

If a British university president has a bright idea (and he does have bright ideas in the early years of office), it would be the height of ineptitude to publish it to his faculty, and fatal to 
issue a directive about it. He must unobtrusively - if possible anonymously - feed it into the organisation, at quite a low level, and watch it percolate slowly upwards .... To do this over some reform urgently needed, requires a singular degree of equanimity; but in Britain the university president who is not prepared to discipline his initiative in this way will fail.

This was said in halcyon days, well before the report of the Jarrett Committee (1985) on 'Efficiency Studies in Universities'. That today's Vice Chancellors may be able to be less circumspect in their use of power to create change is certain, but the extent to which they may be able to be less circumspect and yet effective in creating change in their institutions, which continue to show remarkable abilities at resisting change (see e.g. Lockwood 1987), remains to be explored.

\section{UNIVERSITIES AS SOCIAL SySTEMS}

What the paper has established so far is that organisational change is a systemic phenomenon, and that any strategy of change must take this fact into consideration. However, different organisations are, as systems, very different from each other and the next task is therefore to discuss the systemic nature of universities. This in turn will make it possible to devise change strategies that may be applicable to universities and perhaps test Ashby's approach against these.

Models of university systems, as expressed through their modes of governance have been put forward by e.g. Cohen and March (1986) and the one to which they were most attracted was the one usually described as 'organised anarchy'. The freedom of individual decision making that goes with academic freedom, combined with the responsibility that goes with decision making, both individually and collegially in groups, is akin to the political version of anarchism which advocates the abolition of government and a social system based on voluntary cooperation. Developing these ideas, Birnbaum $(1988,1989)$ has suggested the "cybernetic model' as most suitable for universities, in which the system as a whole is goal directed, but this is achieved not through direction from above, but through multitudinous individual decisions at the level of action. As he points out, in spite of the almost total absence traditionally of tight management structures in universities, they have proved remarkably stable institutions. The stability of such a system depends on constant adjustments and responses through cybernetic controls, i.e. on self-correcting mechanisms at a micro level based on negative feedback, with information flowing freely vertically, both up and down, as well as horizontally. As Middlehurst and Elton (1992) argue, it is the very diversity of sectional interests in a university that establishes the checks and balances which, 
within a common culture, make for a reasonably common purpose and it is the resulting self-correcting mechanism at a micro level which controls the large scale forces which are observable in change processes. It is therefore at this level that the large scale forces must be influenced by the change agent, if they are to be influenced successfully. This is exactly Ashby's point and the extent to which it is still valid today must depend on the extent to which universities are still more cybernetic than hierarchical. It is worth pointing out that universities have always been in part cybernetic and in part hierarchical, but that in the past the part of the organisation which was dominant in any question relating to genuine change was the cybernetic one. I believe that this is still the case today and that therefore any discussion of change must be based primarily on the cybernetic model. The hierarchical model will, however, also play a vital part. As Handy (1984) has pointed out, in professional organisations it is necessary to separate policy and execution, the former being professional and collegial (i.e. cybernetic), the latter hierarchical and bureaucratic.

The complexity of the force field in any real system makes detailed specifications of the forces more of an art than a science, although Senge (1990) gives detailed advice as to how to become more scientific. Paradoxically, a hierarchically managed system, which may appear transparent to top management, is in fact very obscure, since the forces which relate to the managed are mainly hidden, although strong management may feel that it can safely ignore them. If that is so, then simplistic cause and effect models may be valid. If it is not so, then management is in serious trouble. In contrast, in a cybernetic system the many forces which impact on any change, as initiated by a change agent, combine in a non-chaotic manner and in their resultant effect are broadly predictable. It is this which makes it possible to develop change strategies which are based, not on the erroneous idea of a simple cause and effect model, but on a multi-force model.

\section{TOWARDS AN INTEGRATED APPROACH to CHANGE STRATEGIES}

Benne and Chin (1969) have argued for three categories of change strategies, which depend respectively on the use of reason, education and power. One might think that reason would be dominant in academia, but that is not in fact the case, as was well expressed, again by Ashby (1963):

All over the country these groups of scholars, who would not make a decision about the shape of a leaf or the derivation of a word or the author of a manuscript without painstakingly assembling the evidence, make decisions about admission policy, size of universities, staff-student ratios, content of courses and similar issues, based on dubious assumptions, scrappy data and mere hunch. 
Data may have become less scrappy since then, but has anything else changed?

Education, after all the stock in trade of university teachers, does not fare any better. Here is Ashby (1984) again, now in his eighties:

For many years I taught in universities. Like most academics I assumed that the only qualification I needed was expertise in the discipline I taught. It did cross my mind that how to teach might be a discipline in its own right, but I never gave it much thought. I marked thousands of examination scripts without examining what the scripts could teach me about my capacity as teacher and examiner.

A perhaps even more telling point which shows that neither reason nor education are by themselves enough is the well known resistance of academic teachers to their own continuing professional development (CPD), although the provision of CPD for all other professions is a normal part of their practice.

Thus, neither rational argument nor an educational process are likely to play a role on their own in any successful change strategy, although they both have a place, as will be seen. There remains the use of power, which was illustrated by the earlier Ashby quotation, because although it appeared to be about lack of power, it was in fact about its limits. Also it must never be forgotten that power is not necessarily equal to coercion; power is as much needed for carrots which are often more important than sticks. But more of that later.

Experience in other walks of life has shown that generally a key to successful systemic change lies primarily in CPD and - within universities - EHE for instance was successful in general only when it was strongly linked to appropriate CPD. There is no reason to suppose that this prescription does not apply in general to academia, and the three change strategies of reason, education and power must in the first place be applied to the area of academic CPD itself. Here power is needed to bring all except the most dedicated to the point where they take part in appropriate CPD activities, while education is then needed to use these activities to change and develop the attitudes of academics to the point where they are prepared to apply reason to the problems raised by the proposed changes (see e.g. Elton 1984; Boud 1986).

\section{The Three Phases of the Change Process}

Any change happens over an extended time and it is now necessary to discuss how any change strategy should change over time. This was first discussed by Lewin (1961), but the present approach is based on the interpretation of Lewin by Schein (1972), which is rather clearer. 
Lewin identified the three phases in a change process as

unfreezing

changing

refreezing.

Most attention is usually placed on the second phase, but that phase will fail, if the system has not previously been 'unfrozen', i.e. had its stability modified to the point where change became possible. Similarly, without a successful refreezing phase, the innovation will not become institutionalised and therefore will fail. Furthermore, within each phase, there occurs a process of mental development for all those involved, the stages of which were first recognised by Rogers (1967), who identified them as:

awareness of the existence of the proposed change

interest in it

evaluation, i.e. weighing up its consequences

trial, i.e. piloting it to see how it works

adoption, i.e. acceptance of it systemically.

At each stage, rejection of the proposed change is possible and change agents, who tend to be impatient, have to allow time for their clients to go through each stage if they want to avoid rejection. This may be difficult to handle, as different individuals involved in a change process usually move at different rates. (The fact that not only the intended overall change requires an adoption decision, but each phase in the change process, is another matter frequently ignored.)

Unfortunately, change agents tend to find it hard to produce reasons for change which others find convincing and it is therefore very difficult for them to 'rescue' an idea, once it is in danger of rejection. Outright rejection is rarely prevented by presenting increasingly powerful supporting reasons and it may be more effective to introduce temporarily delaying tactics until times may again become more favourable towards change. That rejection is extremely difficult to reverse, once it has happened, has been explained in terms of catastrophe theory (Cryer 1983; Cryer \& Elton 1990). This theory not only provided a mathematical model for the change strategy, developed here, quite generally, but drew particular attention to a 'hysteresis effect', which is a delaying effect between rejection and renewal of interest, in terms of either time delay or the extent of persuasion required.

\section{The unfreezing phase}

Since the system is seen as stable by at least the majority of those within it, it is extremely unlikely that it can be unfrozen by reason or education. Furthermore, the only people who initially are in favour of change are likely 
to be the wholly powerless people who want to persuade their colleagues through CPD, i.e. through reason and education, and they invariably fail, if only because they are rightly perceived as wanting to grind their own axes. Hence unfreezing must depend on the use of power, often from outside the organisation, and the power wielded is usually financial. There have been plenty of examples of this approach over the past fifteen years.

Yet, crude and offensive as this power may have appeared to those at the receiving end, the fact is that it has led to more change in universities in the past fifteen years than in the previous fifty. However, the power exercised should always aim to reduce the forces opposing change to the point where the second phase, that of changing, can start.

There is one further consideration concerning appropriate means of initiating change, namely where to start the change in a system that is inherently stable and resistant to change. Berg and Östergren $(1976,1978)$, who were the first to analyse systemic change in universities, introduced the idea of 'cracks' in the system, i.e. they postulated that in any apparently stable system there are cracks where the stability is less and where change from below can be initiated.

\section{The change phase}

During the change phase, where power, reason and education all must play their part, the balance of driving forces and opposing forces, and the balance of carrot and stick in the use of power constantly change and the skill of the change agent lies in changing the balance appropriately at all times. There are in fact two kinds of change agents involved: those low in the hierarchy who use reason and education, and those high in the hierarchy who mainly use power. This additional feature of successful change, i.e. the delicate pas de deux between those at the top and those at the bottom, with the top facilitating the changes that arise as proposals from below, is a further feature of the process. While these considerations are already in Lewin's writings, they have been expressed most clearly recently by Fullan (1991, p. 91) who, working in the area of schools, postulates the following features for successful change:

1. Small groups of people begin and, if successful, build up momentum.

2. Both pressure and support - i.e. both sticks and carrots - are necessary for success.

3. The relationship between changes in behaviour and changes in belief requires careful consideration.

4. The role of ownership. True ownership is not something that emerges magically at the beginning, but it emerges during a successful change process. 
(Similar considerations have been put forward by Jones and Lewis (1991)). While all four of these steps are valid for both schools and universities, the necessity of finding cracks in a system as a way of initiating change is less important in more authoritarian organisations, such as schools, where change can be initiated also from above. What is, however, needed in all situations is to carry all but a recalcitrant minority along with the change.

As was stated earlier, not all recent attempts at change in universities have been successful and at least part of the reason for this failure lies in the often well meaning desire of those in power, whether inside or outside the universities, to be more than facilitative. Undoubtedly, the power of those lower in the hierarchy, inherent in the cybernetic model, has decreased in recent years, but this has been mainly in the power for good. The power for subtle sabotage has remained largely intact, as can be observed in the phenomenon of compliance, by which academics and institutions go through appropriate motions, which do not however correspond to any reality. This is an extreme example of Fullan's third point being ignored.

\section{The refreezing phase}

Institutions are often so preoccupied with ongoing change that they forget about laying the foundations for the refreezing phase. In fact, very often the resources for creating the change are exhausted at the end of the second phase and resources for the refreezing phase have to be diverted from normal expenditures for ongoing activities. This immediately allows traditionalists to step in and the successful change which has been achieved can then be strangled in this final phase for lack of resources.

I would like to end this section on a personal note. Looking back over many years during which I attempted to achieve change from below, I could have avoided a number of disasters, if I at least had not followed strategies - e.g. persuading where I should have patiently waited for others to persuade - which were in direct opposition to the ones which I have outlined here. Quite generally, I suspect that the strategy presented here is more powerful in the negative than in the positive sense, i.e. not to follow the outlined strategies is almost certain to lead to failure, while following them may, but only may, lead to success.

\section{The ReConciliation of Dialectic OpPosites}

One of the difficulties of the strategy, as presented, is that it requires the reconciliation of concepts which are usually seen as opposites, such as: 
top down and bottom up

carrots and sticks

simplicity and complexity

hierarchical and cybernetic governance

etc

These opposites must be seen in dialectical terms, i.e. their very oppositeness must be used constructively so as to resolve it. An important part of this resolution is the way their balance changes with time, so that for instance in the unfreezing process, sticks are dominant initially, but carrots take over as the process unfolds. One of the surest ways to prevent a change, once initiated, from developing in the intended direction, is to persist with sticks when they are no longer needed to the same extent. Thus while traditional universities initially needed the heavy stick of the Teaching Quality Assessment of the Funding Councils, in order to accept the necessity for the establishment of self assessment and quality assurance processes, if this use of the stick is continued by the recently established Quality Assurance Agency, it will lead to the replacement of self assessment by compliance and a loss of quality. This may be an unintended consequence, but it is wholly predictable.

\section{The Resulting Strategy: A Summary}

It may be useful to step back at this point in order to summarise the strategy, as it has been developed so far. It started with a systems theory, which is concerned with the source of behavioural change within a system. This led to the idea of an analysis of the forces in a system and the way that these forces can be influenced. This in turn showed how different agents of change make different contributions to the change process. Quite separately, there was a developmental model, which described the change process over time in terms of three phases.

The main features of the strategy for successful change, as they have now developed, are very similar to those stated by Berg and Östergren (1977) as 'rules of thumb', but they are now substantially better grounded. Nevertheless, they are in fact extraordinarily simple, but even where they are in line with common sense, they often conflict with common practice and for at times very obvious reasons. In a somewhat oversimplified description, they are:

1. The process of change takes place in three phases - unfreezing, changing and refreezing. 
2. The process of change must be initiated from both 'bottom up' and 'top down', with the bottom having the knowledge and the top the power. Either may be the initiator, but the first real step is for both top and bottom to be committed to the change. The knowledge of those at the bottom often enables them to identify cracks in the system and through these to convince the top of the need for change.

3. The top must use its power, not overtly and directly, but to facilitate the work from the bottom and to provide conditions under which it can prosper. Major failures arise when the top uses its power overtly or the bottom tries to argue its own case.

4. Facilitation should be achieved by reducing the forces opposing change, not by increasing those which support change.

5. The initial unfreezing phase depends on the appropriate use of both stick and carrot. Often most of the stick - and in favourable cases also some of the carrot - come from outside, which makes it more acceptable to those who will have to change, but some of the carrot - and often some of the stick - is almost always the result of internal support from the top. The carrot must be real to be credible, which almost always means that it has a financial component. Reliance on people's good will is permissible initially, but if persisted for too long, is likely to lead to strong rejection.

6. It is essential in the unfreezing phase to achieve a situation where those who have to undergo change feel that the changed future has advantages over the unchanged present and that they come to own the change. This is best done through appropriate changes in working conditions. Effects based on reason or re-education follow. Coercive strategies do not work; they usually lead to compliance. This is the reason why enforced change from the top is so rarely effective.

7. Time needed for each phase of the change process and within each phase must be built in and as far as possible must allow for individual differences.

8. Late rejection, resulting from overhasty change attempts are not uncommon and are particularly difficult to remedy.

9. In successful change, both towards the end of the unfreezing phase and during the whole of the change phase, the balance of carrot and stick moves consistently towards the carrot. Both must decrease, so that at the end of the change phase, any remaining carrot has been absorbed in the change. Stick which persists for too long kills all real change, although the appearance of change may remain.

10. Planning the refreezing phase should start at the latest shortly after the start of the change phase, but probably much earlier. The allocation of 
resources for the refreezing phase is often a particularly contentious matter.

\section{Predictions Based on the Proposed Change Strategy}

Next, I want to refer to two predictions based on the proposed change strategy, one of which enabled me to predict the Enterprise in Higher Education Initiative (EHE) of the UK Department of Employment several years before it was thought of, and another which enabled me to predict a deleterious unintended consequence of a change at a time when it could still have been avoided.

Probably the most successful innovation in university teaching and learning in the past decade has been the EHE Initiative, which started in 1987 and was primarily concerned with changes in curricula. In future, these were to contain a skill component, be interpreted in terms of learning objectives and involve a relationship to the world of work. This was radically different from the traditional academic view of curriculum, which specified a degree course purely in terms of disciplinary content. In addition, the way that skills were to be embedded into the curriculum and the penetration of the initiative to all students in an institution aimed to ensure that the proposed changes became an agent for institutional change and were not sidelined. Inevitably, academic staff development and CPD had to become an essential component, if academics were to take these changes on board.The considerable degree of success of EHE was verified after the event (Biggs et al. 1994), but I claim to have predicted it six years before it started in an article (Elton 1981) where I wrote:

In most universities there are groups of academics who do not wish to be confined within traditional boundaries, who want to develop broader curricula and appropriate teaching methods. Such academics do not need to be 'unfrozen'; what they need is for the forces which oppose them to be reduced. To achieve this, let government and industry provide the meagre resources needed by such groups and protect them by guaranteeing their continued existence for some period, even if at first they do not greatly succeed, which is likely. Put at its lowest, this will enable the traditionalist majority to isolate the troublesome innovators where they can do least harm. At the institutional level, there may even be some gain in kudos .... This will make the universities feel good. Let there also be a clear statement that none of the resources provided for innovations will be at the expense of those for the more traditional functions. This will make the universities feel safe. Overall, the proposed scheme should therefore reduce the forces opposing change.

Once the universities are reassured, staff within them who wish to innovate will also feel safer. To make them feel better, two things are required. The first is a change in the traditional reward structure, which has been frequently advocated and is indeed, 
I believe, slowly coming about. The second is a recognition of their communality of purpose, for instance through the establishment of academically respected learned societies. Both these proposals will provide small supporting forces, when the initial motivational forces begin to slacken off.

Introduced like this, innovations can prove their value. They may then take root, become more familiar and eventually appear less threatening. Who knows, but that traditionalists may see some good in them then and in due course take them over. At that point the innovators become traditionalists and the cycle starts again.

A second prediction, which, while not directly derived from the strategy, demonstrates that unintended consequences need not be unpredictable. It comes from an article on 'UGC resource allocation and the assessment of teaching quality' (Elton 1987), written several years before the establishment of the Higher Education Funding Councils. I then wrote:

Universities have not been slow to realise that under the rules laid down by the UGC, no effort in teaching, however great, can increase the resources allocated to anyone of them. Only efforts in research can do this. Inevitably in circumstances in which universities are fighting for survival, internal pressures will shift effort and resources from teaching to research. The high standards of teaching, for which British universities have an international reputation and which have largely been maintained in increasingly adverse circumstances will decline.

This fairly accurately predicts the relationship of research and teaching today, after three Research Assessment Exercises (McNay 1997). While I am quite proud of what I predicted in the first case, it gives me no pleasure to have played Cassandra in the second.

So while it is as true today, as it was 2500 years ago, that there is nothing constant except change, I hope that I have shown that change is something over which it is possible to exercise some control and that it should be neither accepted fatalistically nor actively mismanaged.

\section{NEW WAYS OF LEARNING}

How then might the strategy developed so far be applied to the problem of curricular change in higher education? I start with a quotation which sets the scene (Coldstream 1998):

When the Higher Education Funding Council for England had the job of assessing the quality of university teaching, it set up a process of 'peer review' for the purpose. The outcome was just what might have been expected: reports on hundreds of university departments were diligent, thoughtful and sensible but - in university terms - entirely conventional in their judgments and - to the eyes of the outside world - deeply conservative. The new quality assurance agency will need to look for methods less bland; in teaching just as in research there need to be prizes for daring, iconoclasm and innovation. 
The crux of this quotation is the need for innovation to be allied to iconoclasm, if the change achieved is to have significance.

\section{THE NEED FOR ICONOCLASM}

Iconoclasm is an attack on established or traditional concepts, principles and laws. It implies that there is a more than normal resistance to change. There are two reasons why such an approach is appropriate with regard to learning and teaching in higher education:

* The external changes which have been imposed on the higher education system are so radical that they call for correspondingly radical internal changes

* Traditional practices in learning and teaching in higher education have been reinforced continually by the almost total absence of serious and consistent reflection on practice and by the equally almost total absence of the use of relevant research.

In consequence, while the first of these points calls urgently for radical change, the second implies that a radical change in culture is required if radical change is to be achieved. The iconoclasm therefore lies first and foremost in the need for a radical change in the culture of universities, so that they

* develop the kind of scepticism and creativity which is normal in research, also in relation to teaching and learning

* appreciate the need for the continuing professional development of all their staff, an activity which they at present apply to every profession except their own

* develop management structures appropriate to innovative teaching and learning.

\section{ICONOCLASM AND INNOVATION}

Coldstream asked for both iconoclasm and innovation, i.e. the two have to be seen as parts of a common strategy. This is a much harder task than that faced by the original religious iconoclasts whose innovation consisted of the creation of places of worship which had no images, a direct consequence of the iconoclasts having smashed those images. The effect was immediate and the power was all with the iconoclasts. The task of 
educational innovators is very different. They want to achieve over a considerable period of time significant change in a well established system in which most of the power continues to reside with the forces of tradition. Perhaps educational innovators should follow Jesus, rather than Cromwell: 'Be ye therefore wise as serpents, and harmless as doves' (St Matthew x, 16), possibly with an added touch of Machiavelli.

\section{Two Kinds of Forces, Two Kinds of InNOvation}

This idea of iconoclastic change can now be linked to the idea of systemic force fields. There are broadly speaking two driving forces for change. The first is the external pressure for greater cost effectiveness, in itself a very negative although very powerful force. The second comes from curriculum research which indicates that university curricula are far from well designed for the students which they serve, and that this applies to all aspects of the curriculum, i.e. aims and objectives, content, methods and assessment. This force is positive but weak. Fortunately the external force can be guided to be in the same direction, but unfortunately this convergence of the two forces is neither inevitable nor common.

The lack of convergence arises in the main in attempts at meeting the need for greater cost effectiveness through solutions which accept the traditional view of university learning and teaching. This view sees teaching primarily as the delivery of knowledge, i.e. it divorces learning from teaching. Not only is this the case in most lecturing, which is inevitably largely non-interactive between teacher and learner, but even where there are more personal interactions between teachers and learners, e.g. through tutorials, the perception that teachers teach and students learn is strongly maintained. Genuine interaction, where students learn from teachers as well as from themselves and each other and where even teachers learn is not frequent and often largely absent from the Oxbridge tutorial. But it is this kind of interaction which, as all research indicates, leads to good learning.

Since traditionally teaching is seen in terms of delivery, with the image that the delivery of knowledge is not so very different from the delivery of biscuits, it is not surprising that manufacturing approaches have been seen as appropriate to the solution of the cost effectiveness problem, i.e. the use of technology, whether through replacing the lecturer by video or the tutor by the computer. Both have their place in the scheme of things, but only if they fit into a pedagogic system which provides a rationale and indicates the form that they should take.

There are in fact two kinds of innovations that come out of research. The first is based on technological change and the second is based on the 
involvement of students actively in the learning process. Both have their place, but the second is overall very much cheaper than the first. Both can lead to greater cost-effectiveness. The two approaches should not of course be seen as separate, but complementary, as has been expressed so eloquently by Laurillard (1993).

\section{ICONOCLASTIC INNOVATION IN MANAGEMENT}

New ways of learning in turn require new forms of institutional management, forms which differ significantly from both traditional ones, where management was comparatively weak and more recent ones, where management has been strong. The new management must be primarily facilitative, but be prepared to lead where necessary and where pressures for reform from within the collegium are perhaps inadequate. The facilitative role is at three levels:

1. creating conditions, through providing resources, recognition and rewards, for creative individuals and groups of staff to put their efforts into innovative teaching and learning, and developing favourable conditions for the continuing professional development of all staff;

2. assuring middle management, i.e. Heads of Departments, that such innovative teaching and learning is as important institutionally as successful research; and

3. updating the institutional administration of teaching and learning to assist and not to handicap innovative work.

Of these three points, it is probably the first which is most accepted. The second runs up against the difficulties created by national funding policies which have so strongly reinforced the preeminence of research over teaching in the past decade, but these difficulties are not insuperable. It is perhaps the third which is least appreciated by traditional management, i.e. the radical difference between administrative support for traditional teaching, which thrives on administrative uniformity and for innovative teaching which thrives on administrative diversity.

There is one other matter that needs clarifying. Innovations need a critical mass if they are to establish themselves, but they have to start with small beginnings. If they start too big, they are likely to crash, if they remain too small they wither away. To avoid both these extremes is another of the tasks of facilitative management and it is an aspect of what is perhaps its greatest task - management for change. 


\section{CONCLUSION}

The most important lesson to be learned from an analysis of successful change in higher education is that it involves - at different times and in different ways - everyone who either wants to achieve change, is affected by the change or has some power over the change, i.e. everyone, but not everyone at the same time and in the same way. If the change results, as it should do, from the kind of understanding of problems which come out of research and reflective practice, then the first people who want the change are mostly very low in the institutional hierarchy, educational researchers, staff developers, etc. For them to push for the change is wholly counterproductive and very frustrating; what they need is powerful allies who are in a position to facilitate the change. There is however a danger there, for these powerful allies may become impatient and try to force the pace of change. This is usually counterproductive, since it sets up resistances among the majority of the people involved, i.e. those in the middle, who may be persuadable, given time and incentives, but will not be rushed, let alone browbeaten.

The problems of introducing innovations are not however confined to the problems arising from the change process itself. Perhaps the most serious problem is that of critical mass. Almost any innovation can thrive, provided it is seen as so insignificant in its effect on the system as a whole that it can safely be ignored. Innovations in the past may have had to start in such a small way and in due course they disappeared because they failed to take root, but usually enough was learned from them to make it possible for them to reappear on a larger scale next time. The introduction of any innovation must not be on too small a scale, but neither must it in the first place be on too large a scale. The critical mass is not, it must be emphasised, merely a question of the number of people directly involved in the innovation, far more is it an involvement of the infrastructure of management, staff and student development, resource allocation and such services as the library, IT services etc.

And that leads finally to practicalities. If the analysis presented in this paper is correct, then the time for piecemeal innovating is past. Innovations must be firmly based on progressive management, which is fully behind the innovation, but at the same time recognises the limitations of power in the face of entrenched traditionalism. It is in fact top management which must be subtle as serpents, while the innovators should be gentle as doves. 


\section{ACKNOWLEDGMENTS}

I wish to acknowledge the assistance of University College London for confirming unawares many of the insights in this paper, and to thank - as so often - Dr Pat Cryer for her invaluable editorial help.

\section{REFERENCES}

Ashby, E. (1963). Decision Making in the Academic World. In P. Halmos (ed.), Sociological Studies in British University Education. University of Keele.

Ashby, E. (1964). The Scientist as a University President, Interdisciplinary Science Review 9, 205-212.

Ashby, E. (1984). Foreword in Brewer, I M. Learning More and Teaching Less. Guildford: SRHE.

Benne, K.D. \& Chin, R. (1969). General Strategies for Effecting Changes in Human Systems. In W.G. Bennis, K.D. Benne \& R. Chin (eds.), The Planning of Change, 2nd edn. New York: Holt Rinehart.

Berg, B. \& Östergren (1977). Innovations and Innovation Processes in Higher Education. Stockholm: UHE.

Berg, B. \& Östergren (1978). Innovation Processes in Higher Education, Studies in Higher Education 4, 261-268.

Biggs, C. et al. (1994). Thematic Evaluation of EHEI. Sheffield: Employment Department, Research Series No 38.

Birnbaum, R. (1988). How Colleges Work: The Cybernetics of Academic Organisation and Leadership. San Francisco: Jossey-Bass.

Birnbaum, R. (1989). The Cybernetic Institution: Toward an Integration of Governance Theories, Higher Education 18, 239-253.

Boud, D. (1986). Learning from Workshop Activities: Extending the Theoretical Base. In P. Cryer (ed.), Training Activities for Teachers in Higher Education. Guildford: SRHE.

Clark, B.R. (1983). The Higher Education System. Berkeley: University of California Press.

Cohen, M.D. \& Marsh, J.G. (1986). Leadership and Ambiguity: The American College President, 2nd edn. New York: McGraw Hill.

Coldstream, P. (1998). Innovation Must not Be Sacrificed, Times Higher Education Supplement, 20 February, p. 16.

Cryer, P. (1983). Materials for Academic Staff Development: A Study of an Innovation. $\mathrm{PhD}$ thesis, University of Surrey, unpublished.

Cryer, P. \& Elton, L. (1990). Catastrophe Theory: A Unified Model for Educational Change, Studies in Higher Education 15, 75-86.

Elton, L. (1981). Can Universities Change? Studies in Higher Education 6, 23-33.

Elton, L. (1984). Workshop Training: Is There a Theoretical Basis? In P. Cryer (ed.), Training Activities for Teachers in Higher Education. Guildford: SRHE.

Elton, L. (1987). UGC Resource Allocation and the Assessment of Teaching Quality, Higher Education Review 19, 9-17.

Elton, L. (1996). Task Differentiation in Universities: Towards a New Collegiality, Tertiary Education and Management 2, 138-145. 
Elton, L. \& Cryer, P. (1994). Quality and Change in Higher Education, Innovative Higher Education 18, 205-220.

Fullan, M.G. \& Stiegelbauer, S. (1991). The New Meaning of Educational Change. London: Cassell.

Handy, C. (1984). Education for Management Outside Business. In S. Goodlad (ed.), Education for the Professions. Guildford: SRHE \& NFER-Nelson.

Jarrett Committee (1985). Report of the Steering Committee for Efficiency Studies in Universities. London: CVCP.

Jones, P. \& Lewis, J. (1991). Implementing a Strategy of Change in Higher Education, Studies in Higher Education 16, 51-61.

Laurillard, D. (1993). Rethinking University Teaching. London: Routledge.

Lewin, K. (1952). Field Theory in Social Science. London: Tavistock.

Lewin, K. (1961). Quasi-stationary Social Equilibria and the Problem of Permanent Change. In W.G. Bennis, K.D. Benne \& R. Chin (eds.), The Planning of Change, 1st edn. New York: Holt Rinehart.

Lockwood, G. (1987). The Management of Universities. In T. Becher (ed.), British Higher Education. London: Allen \& Unwin.

McNay, I. (1997). The Impact of the Research Assessment Exercise on Institutional and Individual Behaviour in English Higher Education. Bristol: HEFCE, M 5/97.

Middlehurst, R. and Elton, L. (1992). Leadership and Management in Higher Education, Studies in Higher Education 17, 251-264.

Pollitt, C. (1987). The Politics of Performance Assessment: Lessons for Higher Education, Studies in Higher Education 12, 87-98.

Rogers, E. (1967). Diffusion of Innovations. New York: Free Press.

Schein, E.H. (1972). Professional Education. The Carnegie Commission on Higher Education, New York: McGraw Hill.

Senge, P.M. (1990). The Fifth Dimension. London: Random House.

Thorpe, D. (1983). De-institutionalisation and Justice. In A. Morris and H. Giles (eds.), Providing Criminal Justice for Children. London: Arnold.

Tutt, N. (1985). The Unintended Consequences of Integration, Educational and Child Psychology 2, 30-38.

Higher Education Research and Development Unit

University College London

1-19 Torrington Place

London WCIE $6 B T$

U.K.

E-mail: l.elton@ucl.ac.uk 
